\title{
ULIXES, Unravelling and exploiting Mediterranean Sea microbial diversity and ecology for xenobiotics' and pollutants' clean up
}

Daniele Daffonchio ${ }^{1 *}$, Francesca Mapelli ${ }^{1}$, Ameur Cherif $^{2}$, Hanan I. Malkawi ${ }^{3}$, Michail M. Yakimov ${ }^{4}$, Yasser R. Abdel-Fattah ${ }^{5}$, Mohamed Blaghen ${ }^{6}$, Peter N. Golyshin ${ }^{7}$, Manuel Ferrer ${ }^{8}$, Nicolas Kalogerakis ${ }^{9}$, Nico Boon ${ }^{10}$, Mirko Magagnini ${ }^{11}$, Fabio Fava ${ }^{12}, \&$ the ULIXES Scientific Team

${ }^{I}$ Department of Food Science and Microbiology, University of Milan, Milan, Italy;

${ }^{2}$ Laboratory of Microorganisms and Active Biomolecules, University of Tunis El Manar, Tunis, Tunisia;

${ }^{3}$ Department of Biological Sciences, Yarmouk University, Irbid, Jordan;

${ }^{4}$ Institute for Coastal Marine Environment, Consiglio Nazionale delle Ricerche, Messina, Italy;

${ }^{5}$ Genetic Engineering and Biotechnology Research Institute, City for Scientific Research \& Technology Applications, Alexandria, Egypt;

${ }^{6}$ Laboratory of Microbiology, Biotechnology and Environment, University Hassan II - Ain Chock, Casablanca, Morocco;

${ }^{7}$ School of Biological Sciences, Bangor University, Bangor, UK;

${ }^{8}$ Institute of Catalysis, Consejo Superior de Investigaciones Científicas, Madrid, Spain;

${ }^{9}$ Department of Environmental Engineering Technical University of Crete, Chania, Greece;

${ }^{10}$ Laboratory of Microbial Ecology and Technology (LabMET), Ghent University, Gent, Belgium;

${ }^{11}$ EcoTechSystems L.t.d, Ancona, Italy;

${ }^{12}$ Department of Civil, Environmental and Materials Engineering, University of Bologna, Bologna, Italy.

*Author for correspondence:

Daniele Daffonchio, DiSTAM, University of Milan, via Celoria 2, 20133, Milan Italy. Tel: +390250319117; Fax: +39-0250319238; E-mail: daniele.daffonchio@unimi.it 
Abstract

The civilizations in the Mediterranean Sea have deeply changed the local environment, especially with the extraction of subsurface oil and gas, their refinery and transportation. Major environmental impacts are affecting all the sides of the basin with actual and potential natural and socio-economic problems. Events like the recent BP's oil disaster in the Gulf of Mexico would have a tremendous impact on a close basin like the Mediterranean Sea. The recently EU-funded project ULIXES (http://www.ulixes.unimi.it/) aims to unravel, categorize, catalogue, exploit and manage the microbial diversity available in the Mediterranean Sea for addressing bioremediation of polluted marine sites. The rationale of the project is based on the multiple diverse environmental niches of the Mediterranean Sea and the huge range of microorganisms inhabiting therein. Microbial consortia and their ecology, their components or products are used for designing novel pollutant- and site-tailored bioremediation approaches. ULIXES exploits microbial resource mining by the isolation of novel microorganisms as well as by novel advanced 'meta-omics' technologies for solving pollution of three major high priority pollutant classes, petroleum hydrocarbons, chlorinated compounds and heavy metals. A network of twelve European and Southern Mediterranean partners is exploring the microbial diversity and ecology associated to a large set of polluted environmental matrices including seashore sands, lagoons, harbors and deepsea sediments, oil tanker shipwreck sites, as well as coastal and deep sea natural sites where hydrocarbon seepages occur. The mined collections are exploited for developing novel bioremediation processes to be tested in ex situ and in situ field bioremediation trials.

Keywords:

Mediterranean Sea; hydrocarbons; chlorinated compounds; degrading microorganisms; marine microbial ecology; metagenomics

\section{Introduction}

The recent BP's oil disaster in the Gulf of Mexico was one of the largest pollution events ever and the US National Institute of Health has launched a long-term follow-up study to assess the oil spill's impact on the resident population (http://news.sciencemag.org/scienceinsider/2011/02/nihbegins-study-of-oil-spills.html?ref=hp). Such disasters, besides devastating ecosystems, also have long-term economic and psychological effects on human communities inhabiting the affected coastal area.

Considering the restricted and semi-enclosed geographical nature of the Mediterranean Sea (e.g. the typical water retention time in Mediterranean is of the order of 70-90 years) the impact of major pollution events could be even stronger than that resulting from the Deepwater Horizon oil spill. Indeed, an important priority of the Euro-Mediterranean countries, since the Barcelona Process, has been the environmental protection of the Mediterranean Sea, by exploiting a NorthSouth and East-West innovative alliance based on the principles of joint ownership, dialogue and co-operation (http://www.eeas.europa.eu/euromed/docs/bd_en.pdf).

The risk of potential pollution loads in the Mediterranean Sea is very high. About 40 oil-related sites (i.e. pipeline terminals, refineries, offshore platforms, etc.) are distributed along the Mediterranean coastal zone, from and to which an estimated amount of 55,000,000 metric tons of crude oil are annually transferred. Since the opening of the Suez Canal, transportation by oil tankers is also a major potential pollution source. Though the Mediterranean represents less than $1 \%$ of the earth's total marine surface, oil tanker traffic accounts for more than $20 \%$ of the global traffic. Moreover, despite the already high potential oil pollution load in the Mediterranean Sea, the general trend of deep sea explorations for new drillings for oil recovery is increasing (Margottini 2011).

Several studies and reports have shown that numerous coastal areas in the Mediterranean Sea (like coastal lakes, lagoons, harbor areas and river outfalls) are heavily polluted with oil hydrocarbons, organic halogenated xenobiotics and heavy metals (UNEP/WHO 1999), frequently with multiple pollutions of different chemical nature that can synergistically increase the overall toxicity (Head 1998). Similarly, it can be difficult to detoxify those sites where pollutants are not promptly treated. In such sites the so called 'aged contaminations' result in the accumulation of weathered pollutants that may be degraded more slowly than the parental compounds (Fava et al. 2003). 
Many of these polluted sites are located within delicate ecosystems, like those of coastal lakes and lagoons that would strongly benefit from the reduction of pollution levels. Most of these sites demand an urgent application of sustainable clean-up strategies based on biological approaches to improve the general environmental quality and the safety for the Mediterranean citizens living in the surrounding areas.

\section{Background \& aims of the project ULIXES}

The rationale of ULIXES considers that a plethora of diverse microbial consortia exploiting different ecological relationships that allow sustaining a range of metabolic processes inhabits the multitude of diverse environmental niches of the Mediterranean Sea that naturally or accidentally are exposed to oil hydrocarbons, halogenated compounds and heavy metals. Such consortia and their single species microbial components can be directly used as inoculants or as source of biological products, like catabolic enzymes (Ferrer et al. 2005) or biosurfactant that can be exploited in pollutant- and site-tailored bioremediation approaches. Characterizing and recovering this diversity, by microorganisms' cultivation and gene mining, and the exploitation of these microorganisms and their components in novel biotechnological processes, can provide the proof of concept that it is possible to establish and exploit, for bioremediation purposes, site-specific collections of microbial strains, mixed microbial cultures, enzymes, biosurfactants and other microbial products. Hence, ULIXES aims to unravel, categorize, catalogue, exploit and manage the microbial diversity available in a series of polluted sites across the South-North and East-West coasts of the Mediterranean Sea. The project aims to manage such resources for developing novel processes based on microbial biotechnology that upon on-site, ex-situ and in-situ applications can address bioremediation of polluted Mediterranean marine sites.

The acronym ULIXES is inspired by Odysseus (Ulysses or Ulixes in the Roman mythology), the legendary Greek king of Ithaca and one of the most popular heroes among the ancient Greek myths. The ULIXES sampling strategy individuated a series of polluted sites located in the same areas of the peregrinations of Odysseus described in the Homer's poem "Odyssey". These span from oil polluted sites in Greece, Egypt, Tunisia (Zrafi-Nouira et al. 2009) and Morocco to sites in marine lagoons (Venice lagoon, Italy) and harbours (Yakimov et al. 2005) contaminated by mixtures of oil hydrocarbons, heavy metals and halogenated compounds, to the Gulf of Aqaba in the Red Sea used as a model for the situation the Mediterranean Sea will face in the future due to global warming. Also deep sea sites where natural seepages of hydrocarbons are considered, like hypersaline waters and sediments from polluted salty coastal lakes and natural deep hypersaline anoxic submarine basins (Borin et al. 2009) and mud volcanoes where natural hydrocarbon seepages occur.

\section{Strategies for the discovery \& application of novel microbial resources}

ULIXES is using three different but integrated strategies for recovering novel microbial resources for bioremediation from the considered polluted sites (Figure 1). The first approach is the establishment of collections of microbes capable of performing given degradation reactions on selected pollutants and/or producing metabolites (e.g. biosurfactants or enzymes) that can improve or promote degradation. This approach is accompanied by a characterization of the overall diversity of the sites by culture-independent molecular ecology approaches. The isolates will be screened for their capacity of producing metabolites that are relevant for the improvement of biodegradation processes, like biosurfactants, extracellular enzymes, polysaccharides and extracellular matrices and their ability to form biofilms. A second strategy is aimed at establishing microbial functions and identifying new enzymes, directly from the environment where microbes thrive, and rely on the metagenomic approach that can overcome the unknown function of a huge number of putative genes. Two approaches are used, i) genome gazing, retrieval and characterization of enzymes from the protein families "known" to facilitate particular reactions, from sequenced genomes of selected microorganisms and metagenomes from selected communities and ii) the direct retrieval from genome/metagenome libraries and consequent characterization of enzymes through the high-end activity screening tools, available to the 
ULIXES consortium. As a third strategy to identify new functions in single cells or complex communities thriving in polluted marine environments, ULIXES will adopt strategies for working at the protein level by proteomic and metabolomic approaches, which take advantage of high throughput tools revealing multiple enzymes by arrayed reactions.

The microbial resources identified as active from the three strategies of functional screening are tested for intensifying, and better tailoring, conventional bioremediation techniques, thus improving their overall sustainability, in a stepwise application at the laboratory pilot and field scale, according to three strategies. With the first strategy, the best pure and/or mixed cultures are tested in batch for the production of new or improved enzymes, new biosurfactants and reductive dechlorination of chlorinated solvents and aged PCBs. Dechlorination will be also tested using nanoparticles, produced on the cell walls of specialized bacteria, i.e. biopalladium (Hennebel et al. 2012). With a second strategy the novel microbial resources are assayed in bioreactors by designing novel processes for ex-situ bioremediation, while with the third strategy the best microbial resource will be assayed in the field or in on-site mesocosms. Major sites are considered in the study: a model site from the north coast of the Mediterranean Sea in the Elefsina Gulf, Greece, a model site from the south coast of the Mediterranean Sea, the seashore of the El Max district, Alexandria, Egypt and a model site from a tropical environment, the seashore of the Aqaba Gulf, Red Sea, Jordan.

\section{The ULIXES Consortium}

ULIXES is a small to medium scale collaborative EU FP7 project (http://www.ulixes.unimi.it/) for Specific Cooperation Actions Dedicated to International Cooperation (CP-FP-SICA) in the theme of Food, agriculture and fisheries and biotechnology in the area of Environmental Biotechnology. The coordinator is from the University of Milan in Italy. The 36-month project started in February 2011 and involves 12 partners from five countries in Europe and four countries on the Southern coast of the Mediterranean Sea (Table 1).

\section{References}

Borin S, Brusetti L, Mapelli F, D’Auria G, Brusa T, Marzorati M, Rizzi A, Yakimov MM, Marty D, De Lange GJ, Van der Wielen P, Bolhuis H, McGenity TJ, Polymenakou PN, Malinverno E, Giuliano L, Corselli C, Daffonchio D (2009) Sulfur cycling and methanogenesis primarily drive microbial colonization of the highly: sulfidic Urania deep hypersaline basin. Proc Natl Acad Sci USA 106:9151-9156.

Fava F, Bertin L, Fedi S, Zannoni D (2003) Methyl-beta-cyclodextrin-enhanced solubilization and aerobic biodegradation of polychlorinated biphenyls in two aged-contaminated soils. Biotechnol Bioeng 81:381-390.

Ferrer M, Golyshina OV, Chernikova TN, Khachane AN, dos Santos VAPM, Yakimov MM, Timmis KN, Golyshin PN (2005) Microbial enzymes mined from the Urania deep-sea hypersaline anoxic basin. Chem Biol 12:895-904.

Head IM (1998) Bioremediation: towards a credible technology. Microbiology 144:599-608.

Hennebel T, De Corte S, Verstraete W, Boon N. Microbial production and environmental applications of Pd nanoparticles for treatment of halogenated compounds. Curr Opin Biotech. In press 8,486.

Margottini L (2012) Gulf drilling disaster triggers scrutiny of Mediterranean oil rush. Science 333:285.

UNEP/WHO (1999) Identification of priority pollution hot spots and sensitive areas in the Mediterranean. MAP Technical Reports Series, No.124, UNEP, Athens.

Yakimov MM, Denaro R, Genovese M, Cappello S, D’Auria G, Chernikova TN, Timmis KN, Golyshin PN, Giluliano L (2005) Natural microbial diversity in superficial sediments of Milazzo Harbor (Sicily) and community successions during microcosm enrichment with various hydrocarbons. Environ Microbiol 7:1426-1441.

Zrafi-Nouira I, Khedir-Ghenim Z, Bahri R, Cheraeif I, Rouabhia M, Saidane-Mosbahi D (2009) Hydrocarbons in seawater and water extract of Jarzouna-Bizerte coastal of Tunisia (Mediterranean Sea): Petroleum origin investigation around refinery rejection place. Water Air Soil Poll 202:1931. 
Fig 1 Schematic overview of the scientific concepts and approaches applied in the ULIXES project

Table 1 Partners in the ULIXES project

\begin{tabular}{|c|c|}
\hline Partner & Expertise \\
\hline University of Milan, Italy & $\begin{array}{l}\text { Project coordination; microbial ecology of } \\
\text { polluted sites; screening of consortia with } \\
\text { reductive dechlorination capabilities }\end{array}$ \\
\hline University of Tunis El Manar, Tunisia & $\begin{array}{l}\text { Collection establishment of pollutant microbial } \\
\text { degraders; microbial ecology of polluted sites; } \\
\text { screening and testing new strains; coordination } \\
\text { of dissemination activities }\end{array}$ \\
\hline Yarmouk University, Jordan & $\begin{array}{l}\text { Sampling from contaminated sites at the Gulf of } \\
\text { Aqaba; isolation of HC degrading microbes; } \\
\text { scaling up of HC degrading cultures; laboratory } \\
\text { and in-situ pilot experiment }\end{array}$ \\
\hline Consiglio Nazionale delle Ricerche, Italy & 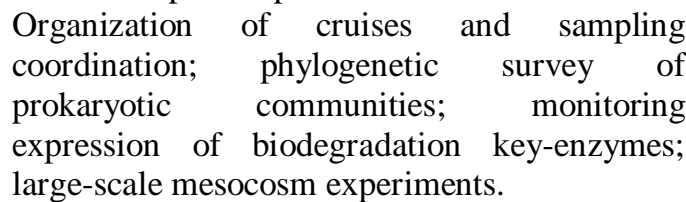 \\
\hline
\end{tabular}

City for Scientific Research \& Technology Sampling from Egypt contaminated sites; Applications, Egypt isolation of degrading microbes; numerical modelling of microbial consortia; optimization of bioremediation inocula in bioreactors; in-situ pilot experiments of the produced consortia

Universitè Hassan II Ain Chock Casablanca, Sampling from contaminated sites in Morocco; Morocco microbial diversity analysis; isolation of degrading microbes, development of HCdegrading consortia.

Bangor University, United Kingdom Establishment of metagenomic and expression libraries; metagenomics; identification of relevant enzymatic processes; Cloning of different HC-related enzymes.

Agencia Estatal Consejo Superior de Construction of a metabolic atlas of polluted Investigaciones Cientificas, Spain samples; annotations of hypothetical genes,

Technical University of Crete, Greece Characterization of biodegradation enzymes. Sampling from contaminated sites in Greece; enrichment of biosurfactant- biofilm-producing microbes; testing new product/processes by microcosms, mesocosms and pilot field tests;

Ghent University, Belgium Isolation of biopalladium (bio-pd) nanoparticles precipitating microbes; novel dechlorination processes catalyzed by bio-pd nanoparticles

EcoTechSystem srl, Italy Sediment sampling in Ancona harbor; physical and chemical characterization of sediments; measure of total prokaryotic abundance, biomass and diversity; assessment of metal and metalloids mobilization in sediments.

Alma Mater Studiorum-Università di Bologna, Sampling Venice Lagoon polluted sediments; Italy

study of PCB-dechlorinating processes; Characterization of biosurfactant productivity and strain ecotoxicology; bioaugmentation experiments for lab-scale PCB dechlorination. 


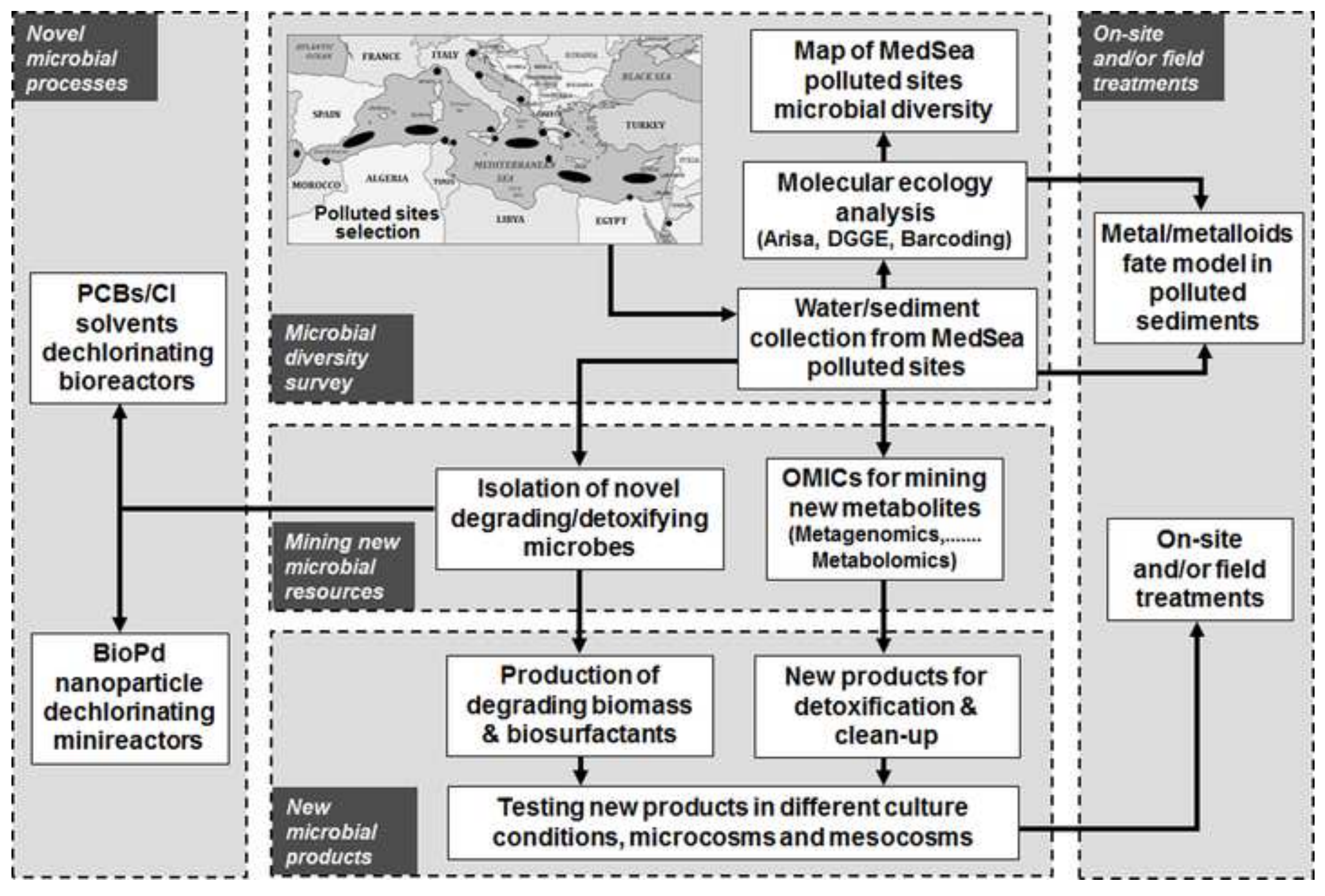

